\title{
Bilateral pneumothorax and pneumomediastinum during upper endoscopy: the role of gastric perforation and of cardiopulmonary resuscitation
}

\section{maneuvers}

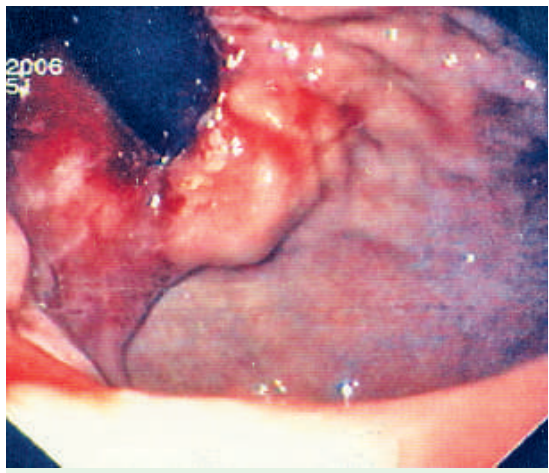

Fig. 1 Through the herniated gastric fundus the cardia shows an irregular and infiltrated mucosa, which bled easily.

We report a case of gastric perforation in a 75-year-old woman who underwent upper endoscopy to investigate dysphagia; the procedure caused pneumoperitoneum, cardiac syncope, pneumomediastinum, and bilateral pneumothorax. We observed endoscopically a dilated esophagus, a substenotic cardia with irregular mucosa ( $\bullet$ Fig. 1), and a large sliding hernia. The cardia was sampled by biopsy. The stomach and duodenum were normal. After endoscopy the patient became cyanotic, poorly responsive, and pulseless, while oxygen saturation dropped to $30 \%$. After Ambu balloon ventilation, cardiac massage, and cardiac defibrillation, a radial pulse reappeared and oxygen saturation rose. Notwithstanding tracheal intubation, oxygen saturation dropped again after a few minutes, breathing sounds were markedly reduced, and the abdomen became tense. X-ray showed bilateral pneumothorax, pneumomediastinum, and pneumoperitoneum, and computed tomography revealed an enlarged cardia region but no perforation ( $\bullet$ Fig. $2 \mathbf{a}$ and Fig. 2 b). Placement of two chest tubes led to rapid improvement. During a second endoscopy, which confirmed the cardia cancer but did not reveal any tear, intraabdominal, but not intrapleural, pressure increased again. At surgery, a 3-mm-wide perforation of the posterior wall of the cardia was found and gastrectomy was performed. The patient was discharged 2 weeks later.
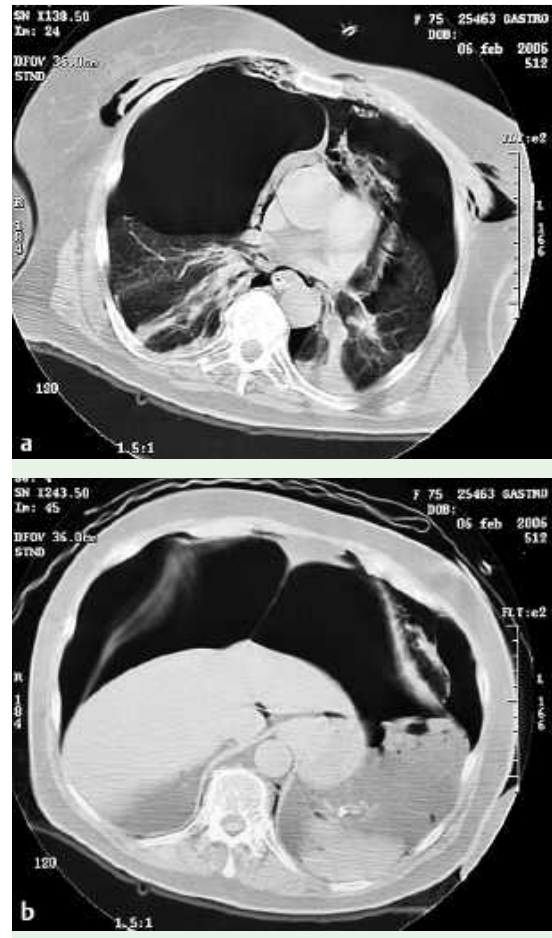

Fig. 2 Computed tomography of (a) chest and (b) abdomen showing bilateral pneumothorax, pneumomediastinum, and pneumoperitoneum, associated with a significant enlargement of the cardia region.

The mechanisms of pneumothorax development after endoscopy vary and depend on the site of perforation [1-3]. Ambu ventilation itself can cause pneumothorax due to increased intra-alveolar pressure $[4,5]$. We suppose that during endoscopy, pressurized air that was inflated into a mechanically produced cardia perforation caused abdominal distension and the first syncope. High intragastric pressure generated by forced ventilation later caused progressive dilatation of the stomach and further air diffusion into the peritoneal cavity, mediastinum, and pleural space, leading to a tense pneumothorax. The increase in intra-abdominal, but not intrapleural, pressure during the second endoscopy suggests a perforation in the peritoneal cavity and an indirect connection with the pleura.

In conclusion, we report an uncommon case of gastric perforation determining syncope, pneumoperitoneum, pneumo- mediastinum, and pneumothorax. These complications highlight the possible risk that resuscitation maneuvers may aggravate a clinical picture of perforation.

\section{Endoscopy_UCTN_Code_CPL_1AH_2AB}

S. Pallotta ${ }^{1}$, G. Manes ${ }^{1}$, E. C. Ferrara ${ }^{1}$, E. Trabucchi ${ }^{2}$, F. Pace ${ }^{1}$, G. Bianchi Porro Division of Gastroenterology, L. Sacco University Hospital, Milano, Italy 2 Division of Surgery, L. Sacco University Hospital, Milano, Italy

\section{References}

1 Minocha A, Richards RJ. Pneumomediastinum as a complication of upper gastrointestinal endoscopy. J Emerg Med 1991; 9: 325-329

2 Rai A, Iftikhar S. Tension pneumothorax complicating diagnostic upper endoscopy: a case report. Am J Gastroenterol 1999; 94: 845-847

3 Maunder RJ, Pierson DJ, Hudson LD. Subcutaneous and mediastinal emphysema, pathophysiology, diagnosis, and management. Arch Intern Med 1984; 144: 1447-1453

4 Hartoko TJ, Demey HE, Rogiers PE et al. Pneumoperitoneum - a rare complication of cardiopulmonary resuscitation. Acta Anaesthesiol Scand 1991; 35: 235-237

5 Parke TRJ. Unexplained pneumoperitoneum in association with basic cardiopulmonary resuscitation efforts. Resuscitation 1993; 26: $177-181$

Bibliography

DOI $10.1055 / \mathrm{s}-2007-966406$

Endoscopy 2009; 41: 97

(c) Georg Thieme Verlag KG Stuttgart · New York . ISSN 0013-726X

\section{Corresponding author}

\section{G. Bianchi Porro, MD}

Divisione e Cattedra di Gastroenterologia

Polo Universitario L. Sacco

Via G. B. Grassi 74

20157 Milano

Italy

Fax: +39-02-39042337

gabriele.bianchiporro@unimi.it 